\title{
ALGUNS DESAFIOS DO FINANCIAMENTO DA EDUCAÇÃO
}

SOME CHALLENGES OF EDUCATION FUNDING IN BRAZIL

\author{
ALGUNOS RETOS DEL FINANCIAMIENTO DE LA EDUCACIÓN
}

Nicholas Davies

Doutor em Sociologia pela USP. Faculdade de Educação da Universidade Federal Fluminense | Brasil E-mail: nidavies1@hotmail.com

REVISTA PEDAGÓGICA

Revista do Programa de Pós-graduação em Educação da Unochapecó | ISSN 1984-1566 Universidade Comunitária da Região de Chapecó | Chapecó-SC, Brasil Como referenciar este artigo: DAVIES, Nicholas. Alguns desafios do financiamento da educação. Revista Pedagógica, Chapecó, v.17, n.33, p. 251-267, Jul./Dez. 2014.

RESUMO: O artigo examina, com base sobretudo em legislação, alguns aspectos problemáticos do financiamento da educação, como a destinação de recursos públicos para instituições privadas (FIES, por exemplo), a isenção fiscal delas (PROUNI, por exemplo), artifícios que retiraram/retiram verbas da educação pública (renúncias fiscais, nãoaplicação da verba legalmente devida), a pequena participação federal no financiamento da educação básica, inclusive no FUNDEF e no FUNDEB, a grande desigualdade tributária entre regiões, Estados e municípios, e o financiamento nos Planos Nacionais de Educação de 2001 e 2014.

PALAVRAS-CHAVE:

educacional. Legislação

Privatização do ensino.
Financiamento educacional.
ABSTRACT: The article examines, based particularly on legislation, some problematic aspects of education funding in Brazil, describing the use of public funds by private educational institutions (the FIES programme, for example), their tax exemption (the PROUNI programme, for example), devices to reduce education funds (tax exemptions, non-compliance of the law requiring a minimum investment on public education), the small federal contribution to basic education funding, including the funding of FUNDEF and FUNDEB, the tax inequality among regions, States and municipalities, and funding in the National Education Plans of 2001 and 2014.

KEYWORDS: Education funding. Educational legislation. Education privatization. 


\section{INTRODUÇÃO}

Este texto pretende apresentar alguns desafios do financiamento da educação. Antes, é preciso esclarecer o caráter do Estado e de suas políticas, pois isso se reflete no financiamento da educação e de outras políticas. Numa sociedade desigual, e não apenas na sociedade capitalista, é um equívoco denominar ações estatais como públicas, uma vez que elas não são elaboradas a partir de iniciativa da maioria da população, de consulta a ela ou visando a seus interesses. Ainda que se apresentem como públicas, caracterizam-se pelo privatismo, já que o Estado representa principalmente uma minoria da população: as várias frações da classe dominante e os segmentos burocráticos privilegiados (Legislativo, Judiciário, setores do Executivo). Exemplo disso é a política fiscal/econômica dos governos, que favorece o empresariado (sobretudo o grande) com toda sorte de incentivos e vantagens. A privatização recente, por exemplo, foi financiada em grande parte pelo Banco Nacional de Desenvolvimento Econômico e 'Social' (BNDES). Exemplos de privilegiamento de segmentos da burocracia estatal são os altíssimos salários e vantagens do Judiciário, do Legislativo e de parte do Executivo.

Entretanto, o Estado reflete não só tais interesses dominantes mas também as contradições sociais (as lutas abertas ou ocultas) entre exploradores/privilegiados e explorados/oprimidos e, por isso, é levado, por pressão dos 'de baixo' e/ou por necessidade de legitimação dos detentores do poder, a atender a interesses dos subalternos, podendo, assim, adquirir certo caráter público. As ditas políticas 'sociais' são manifestações deste potencial público (bastante variável de acordo com o contexto e o país), que, por sua vez, depende da correlação de forças das classes populares/exploradas e das classes dominantes. Assim, se as classes populares/exploradas estiverem organizadas e mobilizadas e se as classes dominantes ou os aparelhos burocráticos estiverem desorganizados ou se virem sem condições de negar concessões às classes populares, estas poderão extrair do Estado uma parcela maior da riqueza social por ele extorquida na forma de impostos. Isso explica, pelo menos em parte, a constituição do chamado 'Estado de Bem-Estar Social' em países da Europa Ocidental, que significou a criação de direitos sociais e a expansão de benefícios sociais. Vale ressaltar que tais avanços 'sociais' não são apenas conquistas (no sentido de serem obtidas graças unicamente à luta dos subalternos), mas também concessões por parte dos donos do poder, que utilizam tais avanços para se legitimar e para enfraquecer qualquer perspectiva mais radical que busque romper com a 'ordem' vigente. No entanto, tais conquistas podem, em contexto diferente, ser retiradas ou diluídas, como os representantes do capitalismo vêm tentando fazer no mundo hoje. 


\section{O FINANCIAMENTO PÚBLICO A INSTITUIÇÕES PRIVADAS DE ENSINO}

Um dos percalços da educação pública é a destinação direta ou indireta de recursos públicos para instituições privadas de ensino. Por exemplo, gozam de isenção fiscal pelo menos desde a Constituição Federal (CF) de 1946 e tiveram/têm acesso gratuito ou subsidiado a verbas públicas em várias legislações, como na primeira LDB (Lei $\mathrm{N}^{0}$ 4.024), de 1961, na Lei No 5.692 (Brasil, 1971), que criou o ensino de $1^{\circ}$ e $2^{\circ}$ Graus, e na atual LDB (Lei No 9.394).

A CF de 1988, em seu art. 212 (parágrafo $2^{\circ}$ ), oferece uma brecha privatista ao considerar, para efeito do cumprimento do percentual mínimo dos impostos vinculados à manutenção e desenvolvimento do ensino (MDE), o montante aplicado pelos sistemas de ensino federal, estadual e municipal e na forma do art. 213. Ora, tais sistemas abrangem não só as escolas estatais, mas também todas as privadas, o que significa que, pela $\mathrm{CF}$, gastos públicos em escolas privadas seriam parte do percentual mínimo. É verdade que, na esfera federal, tal brecha foi aparentemente fechada pela modificação introduzida pela Emenda Constitucional (EC) No 14 (Brasil, 1996a) no parágrafo $1^{0}$ do art. 211, estabelecendo que a "União [...] financiará as instituições de ensino públicas federais". Entretanto, como o parágrafo $2^{\circ}$ do art. 212 não foi alterado, o resultado é uma incongruência, pelo menos na esfera federal, da sua formulação com a nova redação do parágrafo $1^{0}$ do art. 211. Na esfera estadual, distrital e municipal, a brecha continua aberta do ponto de vista legal.

O caput do art. 213 é mais explícito na privatização: os recursos públicos podem ser dirigidos a escolas comunitárias, confessionais ou filantrópicas "sem fins lucrativos", formulação enganosa pois os lucros de tais escolas não são registrados como tais na contabilidade, mas sim como transferências a suas entidades mantenedoras, que na verdade são mantidas e não mantenedoras. $O$ parágrafo $2^{\circ}$ do art. 213 nem se preocupa que tais escolas não tenham fins lucrativos, já que prevê que "As atividades universitárias de pesquisa e extensão poderão receber apoio financeiro do Poder Público.” A Lei No 9.394, no entanto, procurou impedir esta brecha ao estipular que o percentual mínimo se destina ao ensino público, porém considera bolsas de estudo em escolas privadas como MDE. O problema é que as disposições constitucionais preponderam sobre as de qualquer lei.

Um terceiro mecanismo favorável foi o salárioeducação, contribuição social criada em 1964 (pouco meses depois do golpe militar de $1^{0}$ de abril) sobre a folha de pagamento das empresas para financiar o então ensino primário e que até o final de 1996 podia legalmente custear alunos reais ou muitas vezes fictícios no ensino 
fundamental em escolas particulares, tendo sido carreado para pagar legal ou ilegalmente boa parte das matrículas no ensino fundamental privado, segundo Velloso (1987).

Privilégios mais recentes são as isenções fiscais ou de contribuições a instituições privadas de ensino superior (IES) que aderissem ao Programa Universidade para 'Todos' (PROUNI), iniciativa do governo federal que exige como contrapartida para tais isenções o oferecimento de bolsas integrais ou parciais, o que veio a resolver ou pelo menos atenuar a ociosidade ou inadimplência nelas, além do benefício do Financiamento do Estudante do Ensino Superior Privado (FIES), que é formalmente um empréstimo ao estudante, porém se materializa em certificados que as IES privadas utilizam para quitar suas dívidas previdenciárias e outras junto ao governo federal. Vale lembrar que o FIES é o sucessor do Crédito Educativo, criado na década de 1970 pela ditadura militar (ou civilmilitar, segundo outra interpretação). A magnitude do FIES é exemplificada pela Lei No 12.956 (Brasil, 2014), sancionada pela presidente Dilma, em fevereiro de 2014, prevendo $\mathrm{R} \$ 2,5$ bilhões em créditos para ele, pelos créditos de mais de $\mathrm{R} \$ 5,4$ bilhões para ele em 2013, segundo o FNDE (Brasil, MEC, FNDE, 2014), e pelo fato de o PROUNI ter oferecido mais de 1,2 milhão de bolsas integrais e parciais de 2005 a 2013, segundo o Sisprouni (o Sistema do MEC para o Prouni) de 6/11/2013, cujo número expressivo se explica pelo menos em parte porque o FIES prioriza os bolsistas parciais do PROUNI. Graças a estes e outros mecanismos, tais IES privadas cresceram mais do que as públicas, não só durante a ditadura, mas também durante os governos de Fernando Henrique Cardoso (19952002) e do Partido dos Trabalhadores (2003 até hoje).

Como se não bastassem todos estes benefícios, em julho de 2012 a presidente sancionou a Lei $\mathbf{N}^{\mathbf{0}} 12.688$ (Brasil, 2012), para "reestruturar e fortalecer as instituições de ensino superior privado" com dívidas tributárias com a União, a serem pagas em 180 prestações mensais, ou seja, por 15 anos, prevendo também que até $90 \%$ das prestações mensais das dívidas podem ser convertidas em bolsas integrais.

Outro mecanismo é o Fundo de Manutenção e Desenvolvimento da Educação Básica e de Valorização dos Profissionais da Educação (FUNDEB), cuja lei de regulamentação ( $\mathrm{N}^{\circ}$ 11.494) permite a destinação de recursos públicos a creches, pré-escolas e instituições comunitárias, filantrópicas e confessionais de educação especial "sem fins lucrativos" conveniadas com o Poder Público, assim como a cessão de professores da rede pública para trabalhar nelas (Brasil, 2007), permissão que contradiz a própria Lei $\mathrm{N}^{\circ} 11.494$ e também a EC No 53 , que criou o FUNDEB, destinado apenas à educação básica pública. 
Por fim, cabe lembrar os recursos embutidos nos produtos e serviços pagos pela população (neste sentido, são públicos), arrecadados por empresas e repassados a entidades empresariais: é o caso do sistema 'S' (Senai, Sesi, Senac, Sesc etc.), financiado por tributos incluídos em muitos preços, ou seja, são recursos públicos, pois bancados por toda a população, embora privatizados por tais entidades.

\section{ARTIFÍCIOS QUE RETIRARAM/RETIRAM RECEITAS VINCULADAS À EDUCAÇÃO PÚ- BLICA}

Antes de esboçar alguns destes artifícios, cabe lembrar que as verbas legalmente devidas em educação são de dois tipos. Um são as vinculadas à MDE: no mínimo $18 \%$ dos impostos, no caso da União, e 25\%, em Estados, Distrito Federal (DF) e Municípios, segundo o art. 212 da CF de 1988. Tal vinculação, com percentuais e formulações variados desde que começou na $\mathrm{CF}$ de 1934, foi suprimida na CF de 1937, restabelecida na CF de 1946, eliminada novamente, na CF de 1967, só voltando a ser restaurada pela EC No 24 (Emenda Calmon), em 1983. Em alguns Estados (São Paulo, Rio Grande do Sul) e Municípios (Rio de Janeiro), por exemplo, tais percentuais foram elevados nas respectivas Constituições Estaduais e Leis Orgânicas municipais. Incidem sobre a receita líquida de impostos, ou seja, a que fica com o governo federal após a transferência deles para Estados, DF e municípios, e a que fica com os governos estaduais após a transferência para os municípios. Outra receita com origem em impostos que deveria ser contabilizada é a de impostos atrasados (de anos anteriores), que não é registrada na rubrica de impostos, mas sim na da dívida ativa tributária, além do rendimento com a aplicação dos impostos no mercado financeiro, receitas estas que de modo geral os governos durante muito tempo não incluíam na base de cálculo do percentual mínimo. No caso do rendimento financeiro, até hoje a maioria dos governos, talvez todos, não o incluem nesta base.

Outro tipo de receita são as adicionais ao percentual mínimo, algumas com origem em impostos, outras não, tendo vinculação específica, não coincidente necessariamente com o conceito de MDE. Por exemplo, o salário-educação (quase $\mathrm{R} \$ 17$ bilhões de arrecadação nacional em 2013), que não é imposto, só podia ser utilizado no ensino fundamental até o final de 2006 porém não no pagamento de pessoal. Desde 2007 só pode ser empregado na educação básica. Os recursos da merenda escolar, por sua vez, têm origem no salário-educação e também em impostos, mas não são considerados de MDE pela LDB, sendo financiados em grande medida pelo governo federal 
(R \$ 3,5 bilhões em 2013), que também custeia uma série de programas (transporte escolar, dinheiro direto na escola, Plano de Ações Articuladas etc) cujos recursos são adicionais e têm vinculação específica. Só os programas de transporte escolar e dinheiro direto na escola (PDDE) totalizaram quase R $\$ 3$ bilhões em 2013.

Os ganhos (e a complementação federal, se houve/há) com o Fundo de Manutenção e Desenvolvimento do Ensino Fundamental e de Valorização do Magistério (FUNDEF) e o FUNDEB são receitas adicionais (com origem em impostos) calculadas pela diferença entre a contribuição de impostos dos governos estadual e dos municipais para o fundo dentro de cada Estado (os fundos operam só no âmbito de cada Estado) e sua receita. A complementação federal para o FUNDEB gira em torno de R\$ 10 bilhões atualmente.

São vários os artifícios que prejudicaram e prejudicam a educação pública. Um são as renúncias fiscais. Segundo o relatório do Tribunal de Contas da União sobre as contas federais (Brasil, TCU, 2013), o total de renúncias de receitas tributárias/ previdenciárias/creditícias pelo governo federal teria atingido $\mathrm{R} \$$ 216,5 bilhões em 2012, muito superiores às despesas federais em educação (R \$ 66,5 bilhões) e saúde (R \$ 77,3 bilhões). Como sabido, as renúncias consistem em redução total ou parcial de tributos por um certo tempo, a pretexto de incentivar a economia como um todo ou um setor ou região específico. Vale frisar o impacto negativo de renúncias sobre receitas estaduais e municipais, constituídas em parte por impostos federais que integram os Fundos de Participação dos Estados (FPE) e dos Municípios (FPM). Segundo o Ministro José Jorge, relator do TCU sobre as contas, em 2012 houve renúncia de receita do Imposto de Renda e do IPI da ordem de R $\$ 85$ bilhões, com uma redução potencial nos recursos transferidos a estados e municípios de 38 bilhões de reais. Considerando que governos estaduais e municipais também praticam tais renúncias, são astronômicas as perdas sofridas pela educação pública.

Em Santa Catarina, o Tribunal de Contas (Santa Catarina. TCE. 2009) registra em seu relatório sobre as contas estaduais de 2005 a 2008 um prejuízo de cerca de $\mathrm{R} \$ 254$ milhões na educação e R\$ 122 milhões na saúde em conseqüência de impostos desviados da educação e saúde através do Sistema Estadual de Incentivo à Cultura, ao Turismo e ao Esporte (SEITEC) e do Fundo Social. O prejuízo seria causado pelo fato de as empresas poderem recolher uma parte do ICMS aos Fundos Estaduais de Incentivo à Cultura, Turismo e Esporte, em vez de pagar a integralidade do imposto à Secretaria de Fazenda. A consequência é que esta parte do ICMS recolhido para financiar projetos no âmbito de tais fundos não é incluída na base de cálculo do percentual mínimo vinculado à saúde e a educação. O Fundo Social também é financiado por uma parte do ICMS que as empresas recolhem diretamente a ele e igualmente não entra no cálculo dos impostos vinculados à saúde e educação. 
Outro desafio secular é a não-aplicação da verba legalmente vinculada, devida à interpretação equivocada (ou esperta) por governos e Tribunais de Contas (TC). Por exemplo, desde 2004 o governo estadual do Mato Grosso excluiu o imposto de renda por ele arrecadado da base de cálculo, com a concordância/conivência do TC. Durante anos na década de 1990 o governo estadual de Goiás não computou nesta base o Fundo de Participação dos Estados, também com a concordância/conivência do TC. Os governos estaduais do Rio de Janeiro e São Paulo, por sua vez, durante anos na década de 1990 não contabilizaram o salário-educação como acréscimo ao percentual mínimo, com a concordância/conivência dos TCs. Já a prefeitura do Rio de Janeiro durante toda a vigência do FUNDEF não acrescentou os seus ganhos anuais de centenas de milhões de reais ao percentual mínimo. Em Santa Catarina, o governo estadual deixou de aplicar mais de $\mathrm{R} \$ 2$ bilhões legalmente devidos de 1998 a 2008 (Davies, 2011).

Outro prejuízo tem sido a não-inclusão dos rendimentos financeiros com impostos e receitas integralmente vinculadas (salário-educação, por exemplo). Embora registrados contabilmente como uma das rubricas da receita patrimonial, e não de impostos, deveriam ser computados, pois sua origem são impostos ou receitas adicionais. A inclusão de tais rendimentos talvez não fosse necessária se os governos, no caso de não aplicarem num trimestre o montante legalmente devido em MDE, compensassem, no trimestre seguinte, o valor não aplicado no anterior, conforme exigido pela LDB ( $\S 4^{\circ}$ do art. 69), mas é muito pouco provável que essa exigência legal venha sendo cumprida, até porque, com base em estudos que realizo há alguns anos, praticamente nenhum TC faz essa exigência.

A educação perdeu e perde recursos também pelo modo como governos e TCs contabilizam despesas, com uma distinção pouco ou raramente considerada nos orçamentos e prestações de contas. É a distinção entre o conceito de MDE, definido nos artigos 70 e 71 da LDB e complementado pelo Parecer No 26 (Brasil, 1997), do Conselho Nacional de Educação, e o da função orçamentária Educação, previsto na Lei Federal $\mathrm{N}^{0} 4.320$ (Brasil, 1964), que normatiza a elaboração de orçamento público. A merenda escolar, por exemplo, não é considerada como MDE e, portanto, não pode ser paga com o percentual mínimo, embora possa ser (e é, pelo menos parcialmente) financiada pelos repasses feitos pelo FNDE para a alimentação escolar.

Outro equívoco consiste em considerar os inativos como parte da MDE, quando o certo é considerá-los na função Previdenciária. Afinal, não contribuem mais para manter e desenvolver o ensino e sua aposentadoria, em tese pelo menos, deveria ser financiada com suas contribuições e as patronais feitas ao longo da vida ativa, caso não tenham 
sido total ou parcialmente dilapidadas pelos governos. Vale lembrar que o conceito de MDE na LDB abrange apenas remuneração de quem trabalha na educação, e os aposentados recebem proventos, não remuneração, conforme lembram os Manuais da Secretaria do Tesouro Nacional. Em Santa Catarina, o governo estadual computou (e talvez ainda compute) os gastos com os inativos como dispêndios em MDE, segundo o estudo de Davies (2011) com base nos relatórios do Tribunal de Contas do Estado sobre as contas estaduais entre 1998 a 2008. Se tais despesas fossem excluídas, o governo estadual não teria cumprido a exigência constitucional de aplicar o percentual mínimo de $25 \%$ dos impostos.

Deve-se prestar atenção também para a distinção entre despesa empenhada (também denominada de realizada), liquidada e paga, uma vez que nem todo empenho é efetivamente liquidado e, portanto, pago, podendo ocorrer de empenhos emitidos num ano ser cancelados em exercícios posteriores mas os governos não descontarem tais cancelamentos dos supostos gastos em educação. Esta prática de emissão de empenhos (sobretudo para alcançar o percentual mínimo vinculado à MDE) e seu cancelamento em exercício posterior não é incomum e, por isso, se deve estar atento para empenhos não liquidados num ano e que poderão ser cancelados em exercícios posteriores.

Por último, convém atentar para o fato de que prefeituras só podem aplicar os 25\% dos impostos na educação infantil (EI) e no ensino fundamental (EF), conforme determina o art. 11 da LDB. Só podem investir no ensino médio ou superior depois de atender plenamente à EI e ao EF e mesmo assim com recursos fora dos $25 \%$.

\section{A PEQUENA PARTICIPAÇÃO DO GOVERNO FEDERAL}

São muitos (antigos e atuais) os casos de pouco compromisso federal com a educação básica. Por exemplo, o art. 60 do Ato das Disposições Constitucionais Transitórias (ADCT) da CF de 1988 previa que, por 10 anos, o Poder Público deveria aplicar pelo menos 50\% dos percentuais previstos no art. 212 na universalização do ensino fundamental e erradicação do analfabetismo (9\%, no caso da União), o que não foi cumprido pelo governo federal, segundo o TCU. A EC No 14 (Brasil, 1996a), iniciativa do governo FHC, diminuiu este compromisso ainda mais, para o equivalente a 5,4\% dos impostos, porém aumentou a obrigação de Estados, DF e municípios com o ensino fundamental para 15\% dos impostos de 1997 a 2006 e criou o FUNDEF. A EC No 53 (Brasil, 2006), por sua vez, iniciativa do governo Lula que criou o FUNDEB, não prevê compromisso federal específico (a não ser 
a complementação federal) com a educação básica e a erradicação do analfabetismo, como se este já tivesse sido erradicado, o que é desmentido pelo IBGE, que registra cerca de 15 milhões de analfabetos (sem falar nos analfabetos funcionais).

Vale lembrar ainda as várias Emendas Constitucionais que, sem alterar o art. 212 da CF, desvincularam 20\% de impostos federais (entre eles os que compõem os Fundos de Participação dos Estados e dos Municípios) e contribuições sociais (o salário-educação) da educação desde 1994. Os efeitos negativos para Estados, DF e Municípios terminaram no final de 1999, porém continuaram em âmbito federal de 2000 a 2010, em consequência da aprovação e prorrogação várias vezes da Desvinculação da Receita da União (DRU), cujos danos para a educação só extinguiram no final de 2010, em consequência da aprovação da EC No 59/2009 (Brasil, 2009), que, entre outras disposições, estabelece como meta aplicar "recursos públicos em educação como proporção do Produto Interno Bruto". De qualquer modo, o prejuízo destas ECs foi de dezenas de bilhões de reais durante toda a sua vigência.

Com relação aos dois fundos (FUNDEF e FUNDEB) criados pelo governo federal, são frágeis pois consistem basicamente numa redistribuição, dentro de cada Estado, de impostos do governo estadual e das prefeituras. No FUNDEF (1998-2006), o governo estadual e os municipais contribuíam com $15 \%$ de alguns impostos e recebiam principalmente de acordo com o número de matrículas no ensino fundamental regular. No FUNDEB (2007 até 2020), contribuem com $20 \%$ de um número maior de impostos e recebem do fundo de acordo com dois critérios: (1) número de matrículas municipais na educação infantil e no ensino fundamental e matrículas estaduais no ensino fundamental e no ensino médio, (2) valor diferente atribuído a cada nível, modalidade e localização da matrícula.

A fragilidade vem do fato de milhares de governos perderem com eles e, portanto, terem menos condições objetivas de manter e desenvolver o ensino e valorizar o magistério. Os que ganharam/ganham tiveram/têm condições objetivas de cumprir o objetivo proclamado, porém isso não é nenhuma garantia. Por exemplo, as matrículas municipais na educação básica em todos os Estados vêm caindo desde a implantação do FUNDEB, em 2007, embora milhares de prefeituras tenham tido/venham tendo ganhos e complementação federal expressivos com ele.

A fragilidade se deve também ao governo federal contribuir com quase nada ou pouco. No último ano de vigência do FUNDEF, 2006, a complementação federal foi de menos de $1 \%$ (R $\$ 300$ milhões) da receita nacional, formada quase que exclusivamente pela contribuição de Estados e municípios (mais de R $\$ 35$ bilhões). No FUNDEB, 
esta complementação é maior (10\% do total), porém não é tão significativa quando se considera que o governo federal arrecada muito mais do que os governos estaduais e municipais. Vale lembrar que tal complementação era/é definida legalmente como a necessária para a receita per capita em cada Estado alcançar o valor mínimo nacional, não sendo cumprida na vigência do FUNDEF nem pelo governo de FHC nem pelo de Lula. Segundo relatório do GT constituído pelo MEC (Brasil, MEC, 2003), o governo federal teria deixado de contribuir com mais de $\mathrm{R} \$ 12,7$ bilhões devidos de 1998 a 2002. Como essa irregularidade continuou no governo Lula, de 2003 a 2006, a dívida do governo federal com o FUNDEF de 1998 a 2006 deve ter superado $\mathrm{R} \$ 25$ bilhões!

\section{A ENORME DESIGUALDADE TRIBUTÁRIA ENTRE REGIÕES E ESFERAS DE GOVERNO E FINANCIAMENTO NOS PLANOS DE EDUCAÇÃO}

Outro desafio é a enorme desigualdade tributária dentre as diferentes esferas de governo e principalmente a discrepância entre recursos e responsabilidades educacionais, desde a Independência, em 1822, até hoje. O governo central tem a maior receita porém nunca assumiu constitucionalmente oferecer educação básica a toda a população, deixando-a a cargo de Estados e Municípios, geralmente menos privilegiados financeiramente. Os governos estaduais, por sua vez, vêm se desobrigando do ensino fundamental transferindo-o (sem nenhuma base legal) para as prefeituras, sobretudo desde a implantação do FUNDEF, em 1998, embora fiquem com a maior fatia do maior imposto (75\% do ICMS). Segundo o Balanço do Setor Público Nacional, publicado em 2012 pela Secretaria do Tesouro Nacional (Brasil, STN, 2012), a receita líquida (ou seja, após transferência da parcela devida aos municípios) de impostos dos governos estaduais (23 forneceram dados) em 2010 teria sido de cerca de R\$ 282 bilhões (os dados do Distrito Federal foram excluídos, pois o DF não tem Municípios). Os Municípios (4.283 forneceram dados, dos 5.564 existentes na época), por sua vez, teriam tido uma receita de impostos de $\mathrm{R} \$ 182$ bilhões, ou seja, $\mathrm{R} \$ 100$ bilhões a menos do que a dos Estados (R $\$ 282$ bilhões). Já o número de matrículas municipais na educação básica em 2010 (23.722.411) foi maior do que as estaduais (20.031.988). Em outras palavras, as prefeituras arrecadaram bem menos impostos ( $\mathrm{R} \$ 100$ bilhões a menos) para atender a um número maior de matrículas (+ de 3,7 milhões) na educação básica do que os governos estaduais.

Esta desigualdade remete a uma das principais polêmicas no financiamento entre, de um lado, os que priorizam mais verbas, enfatizando a sua falta, e, de outro, 
os que advogam sua melhor aplicação, argumentando que elas já são suficientes. Um exemplo desta polêmica foram os projetos de lei para o Plano Nacional de Educação (PNE) encaminhados em 1998, um pelo MEC, o outro por entidades da dita sociedade civil, sobretudo sindicatos de profissionais da educação e entidades acadêmicas, reunidas no Congresso Nacional de Educação (CONED), em Belo Horizonte, em novembro de 1997. O projeto do MEC previa uma série de metas para 10 anos, porém não definia aumentos dos gastos governamentais, alegando que bastaria a aplicação do percentual mínimo dos impostos e a racionalização no uso dos recursos para a consecução das metas, sem estimar os custos de tais metas e os recursos necessários. Embora seja verdade que a diminuição ou eliminação dos desperdícios ou corrupção dos governos possibilitaria recursos significativos para o cumprimento de tais metas, era pouco provável a concretização das metas do MEC apenas com o uso 'judicioso' dos recursos constitucionais. Se até hoje as práticas dos governantes têm deixado muito a desejar em termos deste uso judicioso, por que razão mudariam a partir do Plano? Como o Plano não apontava elementos concretos que permitissem esperar a aplicação correta e racional dos recursos, as suas metas careciam de fundamentação por não definirem a origem estatal dos recursos adicionais para a sua realização. Isso talvez se explique porque o governo federal na época, seguindo o receituário neoliberal, via a educação como responsabilidade de todos, e não apenas do Estado (tido como incompetente e ineficiente), o que significava transferir à família, aos meios de comunicação de massa, às organizações não-governamentais, leigas ou confessionais, à ação da iniciativa privada, papéis crescentes na oferta da educação que seria responsabilidade estatal.

Ao contrário do MEC, o Plano das entidades participantes do CONED, auto-intitulado 'Proposta da Sociedade Brasileira', previa aumento significativo (10\% do PIB) dos recursos públicos ao longo de 10 anos. Ora, conforme o noticiário revela diariamente, não basta aumentar os recursos, pois eles podem ser dilapidados pelos governantes e pela máquina estatal devido à má gestão, superfaturamentos e tantas outras práticas ilícitas. O simples aumento dos recursos não resultaria necessariamente no atendimento das metas quantitativas e qualitativas do plano, uma vez que a corrupção, o desperdício, a burocratização e tantos outros males podem consumir grande parte do aumento das verbas. Assim, o financiamento é tanto uma questão quantitativa (mais recursos) quanto qualitativa (sua melhor utilização).

A propósito, o Plano sancionado por FHC em 2001 (em vigor até o final de 2010) não previa aumento de recursos em consequência dos vetos presidenciais, nunca derrubados por Lula nem por sua base aliada (eficiente para outras coisas), criando, assim, um plano que não foi plano, 
pois não definia a origem dos recursos para a consecução das metas. Em outras palavras, o plano se tornou mera retórica.

Tal polêmica de certa forma se repetiu na 'novela' do projeto de lei (PL) de PNE encaminhado pelo governo federal ao Congresso Nacional no final de 2010. Previa $7 \%$ do PIB ao final da vigência do PNE, contrariando a proposta das entidades reunidas na Conferência Nacional de Educação (CONAE) em 2010, que defendiam 10\% do PIB em 2014 para a educação pública! A ironia é que a CONAE parece ter sido bancada pelo MEC e as entidades que dela participaram, de modo geral, eram e são alinhadas com o governo federal atual, o que parece indicar que a CONAE foi promovida para o governo se legitimar e criar a ilusão (mais uma!) da participação de entidades da 'sociedade civil', uma vez que a proposta da CONAE para o financiamento do PNE não foi considerada, sendo torpedeada pelos representantes do governo no Congresso Nacional.

O financiamento na Lei do novo PNE (Lei ${ }^{0} 13.005$ ), sancionada em junho de 2014, contém vários pontos fracos. Um é prever no mínimo 10\% do PIB apenas para o final da vigência do PNE, ou seja, em 2024, sendo no mínimo $7 \%$ do PIB no quinto ano, a saber, em 2019. Como não há definição de percentuais e progressividade entre estes períodos, o Poder Público não é obrigado a aplicar nenhum percentual durante eles. Em outras palavras, até o quarto ano não há nenhuma exigência de percentual, assim como do $6^{\circ}$ até o $9^{\circ}$.

Outro problema é a falta de clareza sobre a destinação dos recursos públicos, pois a meta 20 prevê que tais percentuais se destinam à educação pública, porém o $\S 4^{\circ}$ do art. $5^{\circ}$ define que "O investimento público em educação a que se referem o inciso VI do art. 214 da Constituição Federal e a meta 20 do Anexo desta Lei engloba os recursos aplicados na forma do art. 212 da Constituição Federal e do art. 60 do Ato das Disposições Constitucionais Transitórias, bem como os recursos aplicados nos programas de expansão da educação profissional e superior, inclusive na forma de incentivo e isenção fiscal, as bolsas de estudos concedidas no Brasil e no exterior, os subsídios concedidos em programas de financiamento estudantil e o financiamento de creches, pré-escolas e de educação especial na forma do art. 213 da Constituição Federal (grifo meu). Aparentemente, os percentuais se vinculam à educação pública, porém, o Poder Público, no cálculo do investimento público em educação previsto no inciso VI do art. 214 da CF, poderá considerar os recursos públicos destinados a programas que beneficiam instituições privadas, como o Fies, creches, pré-escolas e de educação especial privadas sem fins lucrativos, isenção fiscal (Prouni, por exemplo). 
Outra debilidade é que os governos não arrecadam PIB, mas sim impostos, taxas e contribuições. O PIB é apenas um indicador (muito frágil, tendo em vista a sonegação fiscal generalizada) da produção da riqueza nacional, cuja maior parte não fica com o Poder Público, mas sim com o setor privado. Como cobrar do Poder Público a aplicação de um percentual de uma receita que ele não arrecada? A destinação de $10 \%$ do PIB será dificilmente operacionalizável porque o PIB informa a produção da riqueza nacional (dos governos e iniciativa privada), não apenas dos governos, e será impossível responsabilizar as diferentes esferas de governo (federal, estadual e municipal) ou cada governo individualmente em termos de percentual do PIB. Talvez o único que possa ser responsabilizado em certa medida seja o federal, até porque individualmente detém grande parcela da receita nacional. Quando as responsabilidades financeiras não são claramente definidas, o seu descumprimento é inevitável. Isso é complicado ainda mais porque o regime de colaboração até hoje não foi definido e a Lei prevê sua regulamentação somente no prazo de 2 anos após a aprovação do PNE.

Além disso, mesmo que governos indiquem nos orçamentos e balanços estarem aplicando o correspondente a $10 \%$ do PIB, nada garante que isso esteja acontecendo na prática, pois não é incomum eles declararem dispêndios que não representam despesas reais. Tampouco adianta destinar $10 \%$ do PIB para a educação pública se grande parte dos recursos for absorvida pela burocracia, que é quem controla a destinação das verbas. É sabido que boa parte dos recursos públicos se perdem nas atividadesmeio e não beneficiam as atividades-fim (a escola e a sala de aula) e o aumento de recursos para a educação não garante necessariamente o atendimento de certas metas de ampliação de vagas, contratação de profissionais da educação e funcionários, se a burocracia educacional não for contida em sua voracidade. Em síntese, não basta garantir mais recursos. É preciso também assegurar a sua efetiva aplicação (e não apenas contábil) na melhoria das atividades-fim (o professor e o aluno).

Outra fragilidade é que a Lei não poderá ser cumprida imediatamente, pois muitas das ações nela previstas dependerão de leis posteriores. A mais importante é a regulamentação do regime de colaboração entre a União, Estados, Distrito Federal e Municípios, com implicações na ação supletiva e redistributiva da União e dos Estados (prevista no art. 211 da CF). Trocando em miúdos, se os entes federados não tiverem condições de garantir o padrão mínimo de qualidade de ensino, a União e os Estados deveriam exercer tal ação (art. 75 da LDB). Tal regulamentação até hoje não foi feita e a Lei a posterga ainda mais, segundo a estratégia 20.9, que prevê, no prazo de 2 anos, lei complementar neste sentido. 
Outra estratégia que dependerá de lei posterior, também no prazo de 2 anos após a sanção da Lei $\mathrm{n}^{\mathrm{o}}$ 13.005, é a que definirá o custo aluno-qualidade inicial, a ser substituído pelo custo aluno-qualidade no prazo de 3 anos, prevendo-se complementação federal a Estados, Distrito Federal e Municípios que não alcançarem tal valor do custo-aluno-qualidade. Em suma, como a lei do PNE foi sancionada em 2014, só em 2016 (provavelmente mais para o final do ano) termina o prazo para a elaboração da Lei do Custo Aluno-Qualidade inicial e a regulamentação do regime de colaboração. Até lá não se poderá exigir legalmente a ação supletiva e redistributiva da União e dos Estados, conforme previsto na LDB. Uma fragilidade deste cálculo é que ele será monopolizado pelo INEP, sem nenhuma participação ou influência efetiva de entidades da sociedade civil. No máximo tal cálculo será "acompanhado pelo Fórum Nacional de Educação, pelo Conselho Nacional de Educação e pelas Comissões de Educação da Câmara dos Deputados e de Educação, Cultura e Esportes do Senado Federal" (Brasil, 2014). Para este caso, no entanto, a Lei não prevê o controle social que advoga sobre os recursos aplicados em educação.

\section{CONSIDERAÇÕES FINAIS}

O artigo examinou alguns aspectos problemáticos do financiamento da educação, como a destinação de recursos públicos para instituições privadas (FIES, por exemplo), a isenção fiscal delas (PROUNI, por exemplo), artifícios que retiraram/retiram verbas da educação pública (renúncias fiscais, não-aplicação da verba legalmente devida), a pequena participação federal no financiamento da educação básica, inclusive no FUNDEF e no FUNDEB, a grande desigualdade tributária entre regiões, Estados e municípios, e o financiamento nos Planos Nacionais de Educação de 2001 e 2014. Um dos grandes desafios é não só aumentar as verbas da educação, mas também garantir que elas sejam aplicadas pelo menos nos fins legalmente devidos, o que exige o controle social por parte sobretudo dos educadores, instrumento fundamental para a desprivatização do Estado e sua democratização substantiva.

\section{REFERÊNCIAS}

BRASIL. Congresso Nacional. Constituição da República Federativa do Brasil. Brasília: Senado Federal, 1988. Disponível em <http://www.planalto.gov. br>. Acesso em: mar. 2014. 
BRASIL. Emenda Constitucional No 14, de 12 de setembro de 1996. Modifica os arts. 34, 208, 211212 da CF e dá nova redação ao art. 60 do Ato das Disposições Constitucionais Transitórias. Diário Oficial da União, Brasília, DF, 13 set. 1996a. Disponível em: <http://www. planalto.gov.br/> Acesso em: 10 dez. 2010.

BRASIL. Emenda Constitucional $\mathrm{N}^{\circ} 53$, de 19 de dezembro de 2006. Dá nova redação aos arts. $7^{\circ}, 23,30$, 206, 208, 211 e 212 da Constituição Federal e ao art. 60 do Ato das Disposições Constitucionais Transitórias. Diário Oficial da União, Brasília, DF, 20 dez. 2006.

BRASIL. Emenda Constitucional No 59, de 11 de novembro de 2009. Acrescenta $\S 3^{\circ}$ ao art. 76 do Ato das Disposições Constitucionais Transitórias para reduzir, anualmente, a partir do exercício de 2009, o percentual da Desvinculação das Receitas da União incidente sobre os recursos destinados à manutenção e desenvolvimento do ensino de que trata o art. 212 da Constituição Federal, dá nova redação aos incisos I e VII do art. 208, de forma a prever a obrigatoriedade do ensino de quatro a dezessete anos e ampliar a abrangência dos programas suplementares para todas as etapas da educação básica, e dá nova redação ao $\S 4^{\circ}$ do art. 211 e ao $\S 3^{\circ}$ do art. 212 e ao caput do art. 214, com a inserção neste dispositivo de inciso VI. Diário Oficial da União, Brasília, DF, 12/11/2009.

BRASIL. Lei No 10.260, de 12 de julho de 2001. Dispõe sobre o Fundo de Financiamento ao Estudante do Ensino Superior e dá outras providências. Diário Oficial da União, Brasília, DF, 13/7/2001.

BRASIL. Lei No 11.096 , de 13 de janeiro de 2005. Institui o Programa Universidade para Todos - PROUNI, regula a atuação de entidades beneficentes de assistência social no ensino superior; altera a Lei $\mathrm{N}^{0} 10.891$, de 9 de julho de 2004, e dá outras providências. Diário Oficial da União, Brasília, DF, 14/1/2005.

BRASIL. Lei No 11.494, de 20 de junho de 2007. Regulamenta o Fundo de Manutenção e Desenvolvimento da Educação Básica e de Valorização dos Profissionais da Educação - FUNDEB, de que trata o art. 60 do Ato das Disposições Constitucionais Transitórias; altera a Lei $\mathrm{n}^{0}$ 10.195, de 14 de fevereiro de 2001; revoga dispositivos das Leis nos 9.424, de 24 de dezembro de 1996, 10.880, de 9 de junho de 2004, e 10.845, de 5 de março de 2004; e dá outras providências. Diário Oficial da União, Brasília, DF, 21 jun. 2007.

BRASIL. Lei No 12.688 , de 18 de julho de 2012. Institui o Programa de Estímulo à Reestruturação e ao Fortalecimento das Instituições de Ensino Superior (PROIES). Diário Oficial da União, Brasília, 19/7/2012. Edição extra. 
BRASIL. Lei No 12.956 , de 27 de fevereiro de 2014 . Abre crédito extraordinário, em favor de Operações Oficiais de Crédito, no valor de $\mathrm{R} \$ 2.531 .486 .253$,oo, para o fim que especifica. Diário Oficial da União, Brasília, DF, $28 / 2 / 2014$.

BRASIL. Lei No 13.005, de 25 de junho de 2014. Aprova o Plano Nacional de Educação e dá outras providências. Diário Oficial da União, edição extra, Brasília, DF, 26 de junho de 2014.

BRASIL. Lei $\mathrm{N}^{\circ}$ 5.692, de 11 de agosto de 1971. Fixa Diretrizes e Bases para o ensino de $1^{\circ}$ e $2^{\circ}$ graus e dá outras providências. Diário Oficial da União, Brasília, DF, 12/8/1971.

BRASIL. Lei No 9.394, de 20 de dezembro de 1996. Estabelece as diretrizes e bases da educação nacional. Diário Oficial da União, Brasília, DF, 23 dez. 1996b.

BRASIL. MEC. Conselho Nacional de Educação. Parecer No. CP 26/97, de 2 de dezembro de 1997. Interpreta o financiamento da educação na LDB. Brasília, 1997.

BRASIL. MEC. FNDE. Relatório de gestão: 2013. Brasília, DF, 2014. Disponível em www.fnde.gov.br. Acesso em: 10 mai. 2014.

BRASIL. MEC.Plano Nacional de Educação: proposta do Executivo ao Congresso Nacional. Brasília: MEC/ Inep, 1998.

BRASIL. MEC. Relatório do GT sobre o cálculo do valor mínimo do FUNDEF. Brasília, 2003. Disponível em <www.mec.gov.br>. Acesso em: set. 2003.

BRASIL. Ministério da Fazenda. Secretaria do Tesouro Nacional. Balanço do Setor Público Nacional. Brasília, 2012. Disponível em: www.stn.fazenda.gov.br. Acesso em: jul. 2012.

BRASIL. TCU (Tribunal de Contas da União). Relatório e parecer prévio sobre as contas do governo da República. Exercício de 2012. Item "Renúncia de receitas: benefícios tributários, financeiros e creditícios". Disponível em: www.tcu.gov.br. Acesso em: 20 abr. 2014.

CONED (Congresso Nacional de Educação). Plano Nacional de Educação. Proposta da Sociedade Brasileira. Plano elaborado pelas entidades participantes do II Coned (Congresso Nacional de Educação), realizado em Belo Horizonte, de 6 a 9 de novembro de 1997.

DAVIES, Nicholas. A frágil confiabilidade do Tribunal de Contas de Santa Catarina na fiscalização dos recursos da educação: governo estadual deixou de aplicar mais de $\mathrm{R} \$ 2,1$ bilhões em educação de 1998 a 2008 mas TC aprovou as contas estaduais. Perspectiva (revista do Centro de Educação da Univ. Fed. de Santa Catarina), v. 29, n. 1, jan./jun. 2011. 
DAVIES, Nicholas. Fundeb: a redenção da educação básica? Campinas: Autores Associados, 2008.

DAVIES, Nicholas. O financiamento da educação: novos ou velhos desafios? São Paulo: Xamã, 2004.

DAVIES, Nicholas. O Fundef e as verbas da educação. São Paulo: Xamã, 2001a.

DAVIES, Nicholas. Tribunais de Contas e educação. Quem controla o fiscalizador dos recursos? Brasília: Editora Plano, 2001b.

MELCHIOR, José Carlos de Araújo. Mudanças no financiamento da educação no Brasil. Campinas: Autores Associados, 1997.

SANTA CATARINA. Parecer prévio sobre as contas prestadas pelo Governador do Estado: exercício de 2008. Florianópolis: TCE, 2009.

VELLOSO, Jacques. A nova lei de Diretrizes e Bases da Educação e o financiamento do ensino: pontos de partida. Educação \& Sociedade, São Paulo, n. 30, 1988.

VELLOSO, Jacques. Política educacional e recursos para o ensino: o salário-educação e a Universidade Federal. Cadernos de Pesquisa, São Paulo, n. 61, 1987. 